\title{
Experimental and modelling study of interaction between friction and galling under contact load change conditions
}

\author{
Xiao YANG ${ }^{1}$, Yiran HU ${ }^{1}$, Lemeng ZHANG ${ }^{1}$, Yang ZHENG ${ }^{1}$, Denis J. POLITIS ${ }^{2}$, Xiaochuan LIU $^{3}$, Li-liang WANG ${ }^{1, *}$ \\ ${ }^{1}$ Department of Mechanical Engineering, Imperial College London, London SW7 2AZ, UK \\ ${ }^{2}$ Department of Mechanical and Manufacturing Engineering, University of Cyprus, Nicosia 1678, the Republic of Cyprus \\ ${ }^{3}$ School of Mechanical Engineering, Xi'an Jiaotong University, Xi'an 710049, China \\ Received: 23 February 2021 / Revised: 23 April 2021 / Accepted: 27 May 2021 \\ (C) The author(s) 2021.
}

\begin{abstract}
The galling process remains one of the least understood phenomena in metal forming. The transfer of material from a work-piece onto the tool surface can cause an evolutionary increase in friction coefficient (COF) and thus the use of a constant COF in finite element (FE) simulations leads to progressively inaccurate results. For an aluminium work-piece, material transfer, which has history and pressure dependency, is determined by a dynamic balance between the generation and ejection of wear particles acting as a 'third body' abrasive element at the contact interface. To address this dynamic interactive phenomenon, pin-on-disc tests between AA6082 and G3500 were performed under step load change conditions. The COF evolutions, morphologies of the transfer layer and its cross-section were studied. It has been found that contact load change will disequilibrate and rebuild the dynamic balance and high load will increase the generation and ejection rate of third body and vice versa. Moreover, based on the experimental results, an interactive model was developed and presented to simulate the dynamic formation process of the aluminium third body layer under load change conditions, enabling multi-cycle simulations to model the galling distribution and friction variation.
\end{abstract}

Keywords: galling; load change; interactive friction model; metal forming; AA6082 aluminium alloy

\section{Introduction}

Galling is a form of surface damage due to adhesive wear between two or more sliding solids and is commonly found in metal forming operations resulting in work-piece material adhering to the tool surface $[1,2]$. This phenomenon occurs frequently in the forming of 'soft' materials such as aluminium sheet metal against steel tooling material, where after repeated operations, a transfer layer originating from the work-piece forms on the tool surfaces [3-7]. This transfer layer may lead to products with low surface quality and damage functional surfaces on the tools. Although the application of lubricant and coating can partly suppress aluminium transfer [5, 8-11], there is still no effective solution to prevent aluminium transfer during forming. To enable the prediction of galling distributions and friction evolutions within tools and to further predict tool life in multi-cycle loading conditions, there is a fairly urgent requirement to study and model the progress of aluminium transfer.

Galling is a system response rather than a material property. It depends on contact conditions, such as counterpart material, surface roughness, sliding distance, contact pressure, and temperature, as well as the contact history, which cause numerous interrelationships and interdependencies. The transfer mechanism has been identified as wear particles that detach from the workpiece and transfer to the counterpart by either adhering as lumps or covering as loose wear particles [9, 12-14]. These transferred tribo-materials known as 'third bodies', to distinguish

* Corresponding author: Li-liang WANG, E-mail: liliang.wang@imperial.ac.uk 
from the two original sliding bodies, are produced by mechanical and chemical interactions of the contact couple during sliding, and can be both macro/micro structurally and chemically different from the source material [14-18]. The chemical composition of the aluminium third body formed at room temperature with steel has been described in the literature as being a combination of aluminium-oxygen solid solutions and hydroxylated materials [19-21]. The initial surface roughness of the contact pair was found to be an important trigger for transfer where a high surface roughness may result in severe galling [4, 13, 22-24]. The formation of a transfer layer with increasing sliding distance can be modelled as two states: 1) the initial running in state, where the mass of aluminium transfer layer gradually increases until stage (2) (S2); and 2) a critical level [13], namely the steady stage, which is characterised by a dynamic balance of the mass/volume [25], the thickness [22, 23, 26] and the galling area of the transfer layer [4, 27]. It was also found that both the formation rate and the saturated volume of the transfer layers increase with increasing contact load [26]. In the early research by Bowden and Tabor [28], adhesive wear was described as the forming and breaking of adhesive junctions, which suggests that tangential stresses may be simultaneously generated with detachment and transfer of material fragments. For the sliding of aluminium against tool steels, the interaction between aluminium transfer wear and friction was commonly observed by the evolutions of both the coefficient of friction (COF) and transfer layer formation [2, 5, 8, 22, 23, 29]. A holistic interactive study was suggested in the investigation of the relationship between friction and adhesive wear [30-32].

Adhesive wear, material transfer, and friction are the three main responses in the dry sliding contact between aluminium and tool steel. The evolution of adhesive wear is a significantly studied tribo-system response. The Holm-Archard equation and its variants have provided great flexibility for modelling wear volumes at the equilibrium state [25, 30, 32-37], and the transition of wear evolution in the running in state was modelled by Yang [38, 39]. Based on these adhesive wear models, the interaction between the responses of friction and transfer were modelled: A statistical model for describing the growth of third body particles or lumps and the generation of adhesion force has been developed [22]. Subsequently de Rooij et al. [23] proposed a model to predict material transfer phenomenon for a single asperity, in which the morphology variation and the interactive resisting force generated by a lump was modelled. The concept of solid third body was gradually applied into galling analysis to holistically investigate the three responses in the tribo-system between the original mating pairs and the transfer layer [25, 40,41]. In the third body model [25], the formation of transfer layer was described as a competition between the generation and ejection of wear particles until a dynamic equilibrium is reached. However, although these physics-based models provide insights into the chemical and mechanical nature of galling, the complexities and lack of insight of dynamic forming processes limit their further industrial application.

On the other hand, modelling of the friction evolution caused by galling can be treated as a nonlinear dynamic problem in tribological modelling. Instead of understanding the sophisticated interactions between friction, wear, and transfer generations, dynamic models focus on accurate modelling of mechanical responses in order to model the correct operation of a system. The history and pressure dependencies of friction were addressed in many dynamic friction models [42, 43] with several models even specifically designed for sheet metal forming [44-51]. However, these non-linear dependencies were always caused by lubrication, abrasive running in, and the start/stop of the tribosystem rather than galling. Although the interaction between friction and galling has been confirmed in the literature, there are few dynamic models developed to model the formation process of galling. In addition, the conditions of sheet metal forming also provide unique dynamic characteristics compared to other dynamic systems: 1) due to the sudden contact and detachment of tools, rapid change of contact load, or 'load jump', which widely exists in metal forming [52-56]; and 2) the shape complexity of forming tools combined with the flow of work-piece material generates uneven spatial and historical distribution of sliding distance and contact pressure, and thus leads to an uneven distribution of galling and friction 
on tools [57]. These characteristics provide challenges both to the existing friction/wear models as well as the previous study of galling mechanisms. Therefore, the development of a holistic model capable of predicting tool damage caused by load-change through the interaction of adhesive wear, material transfer, and friction is essential to accurately predict metal forming processes and significantly improve component quality.

In the present study, the dynamic effects of contact load on aluminum adhesive wear in the running in state are presented. Pin-on-disc tests between AA6082 pin and G3500 disc were performed at step load change conditions to explore the pressure and history dependencies of dynamic transfer mechanisms. Results that show the interaction between friction increase and aluminum transfer were analysed by COF evolutions and micrographics. The validity of an interactive friction model developed in the previous study [58] was investigated and verified to accurately model the tool damage caused by galling incorporating load changes as a driving variable. This model has enabled the prediction of galling area and COF variations under load changing conditions with the formation of an aluminium transfer layer over time.

\section{Methodology}

\subsection{Materials}

Pin-on-disc tests were performed to determine the effect of contact load change at the running in state on aluminium adhesive wear in order to: 1) quantitatively measure its effect on the COF and galling area, and 2) to verify an interactive friction model. The flat pin was made of AA6082 aluminium alloy with a diameter of $2 \mathrm{~mm}$, surface roughness $(R a)$ of $(486 \pm 35) \mathrm{nm}$ and hardness of $(115 \pm 5) \mathrm{HV}$. The disc was made of G3500 cast iron with surface roughness $(R a)$ of $(126 \pm 19) \mathrm{nm}$ and hardness of $(209 \pm 18) \mathrm{HV}$, which represented the tool material.

\subsection{Testing methods}

The pin-on-disc experiments were conducted at room temperature with a linear sliding speed of $50 \mathrm{~mm} / \mathrm{s}$ and the radius of the wear track was $5 \mathrm{~mm}$ (Fig. 1).

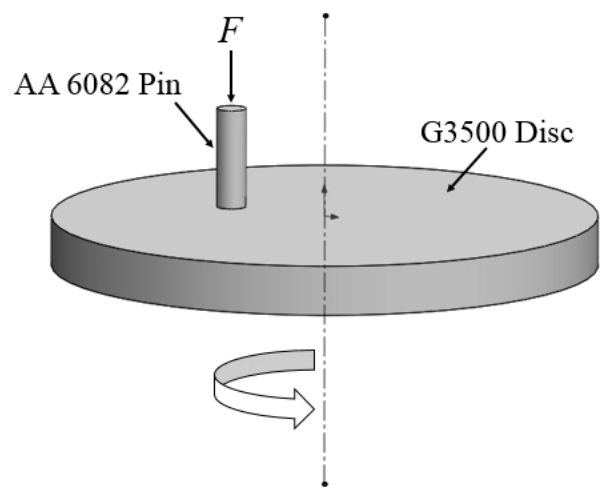

Fig. 1 Schematic illustration of a pin-on-disc test. $F$ represents the normal load applied on the pin.

The flat contact between the pin and disc was selfaligned in less than ten laps. As shown by the test matrix in Table 1, the step change of contact load was characterized by stages with a certain sliding distance. Two conditions of contact load change, test 1 with load increase from 2 to $10 \mathrm{~N}$ and test 2 with load decrease from 10 to $2 \mathrm{~N}$, were conducted. To obtain clear results of the effects of load change, the sliding distance of stage 1 (S1) was designed to reach approximately the middle of the running in state; and S2 to reach the equilibrium state. For S1, 200 laps of sliding distance under $2 \mathrm{~N}$ and 100 laps under $10 \mathrm{~N}$ were used. COF evolutions were recorded in real time with an acquisition rate of $160 \mathrm{~Hz}$. Each test condition to generate the COF evolutions was repeated three times. The obtained COF data were smoothed and presented by average values with standard deviations (SDs) of the three repetitions in Figs. 2 and 3. In addition, a series of experiments conducted under constant load (Table 2) were designed to compare the results with tests 1 and 2 . In addition, to calibrate the tests, tests 4 and 6 were conducted to represent the morphology condition at the end of S1 in tests 2 and 1 respectively. Tests 5 and 7 were conducted under the constant loads of 2 and $10 \mathrm{~N}$ respectively and were completed at the equilibrium state enabling a comparison with the COF evolutions under load change conditions. The load effect on wear particles was studied by comparing tests $3(2 \mathrm{~N})$ and $6(10 \mathrm{~N})$.

\subsection{Characterisation of galling}

Surface morphologies of the cast iron disc were 
Table 1 Test matrix of load change test.

\begin{tabular}{|c|c|c|c|c|c|c|c|c|c|}
\hline \multirow[b]{2}{*}{ Test No. } & \multicolumn{4}{|c|}{$\mathrm{S} 1$} & \multicolumn{4}{|c|}{$\mathrm{S} 2$} & \multirow[b]{2}{*}{ Note } \\
\hline & $\begin{array}{l}\text { load } \\
(\mathrm{N})\end{array}$ & $\begin{array}{c}\text { Contact pressure } \\
(\mathrm{MPa})\end{array}$ & $\begin{array}{l}\text { Sliding } \\
\text { laps }\end{array}$ & $\begin{array}{l}\text { Distance } \\
(\mathrm{m})\end{array}$ & $\begin{array}{l}\text { Load } \\
(\mathrm{N})\end{array}$ & $\begin{array}{c}\text { Contact pressure } \\
(\mathrm{MPa})\end{array}$ & $\begin{array}{l}\text { Sliding } \\
\text { laps }\end{array}$ & $\begin{array}{l}\text { Distance } \\
\quad(\mathrm{m})\end{array}$ & \\
\hline 1 & 2 & 0.64 & 200 & 6.28 & 10 & 3.18 & 600 & 18.85 & $\begin{array}{l}\text { Load increase, } \\
\text { S2(inc) }\end{array}$ \\
\hline 2 & 10 & 3.18 & 100 & 3.14 & 2 & 0.64 & 700 & 21.99 & $\begin{array}{l}\text { Load decrease, } \\
\text { S2(dec) }\end{array}$ \\
\hline
\end{tabular}

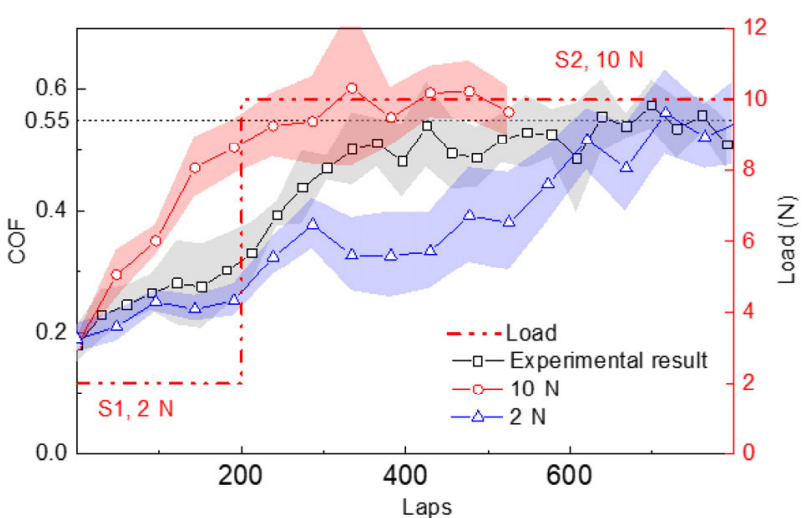

Fig. 2 Comparing COF evolutions between load increase and constant loads. Symbols represent average COFs; envelopes represent SDs of three repetitions.

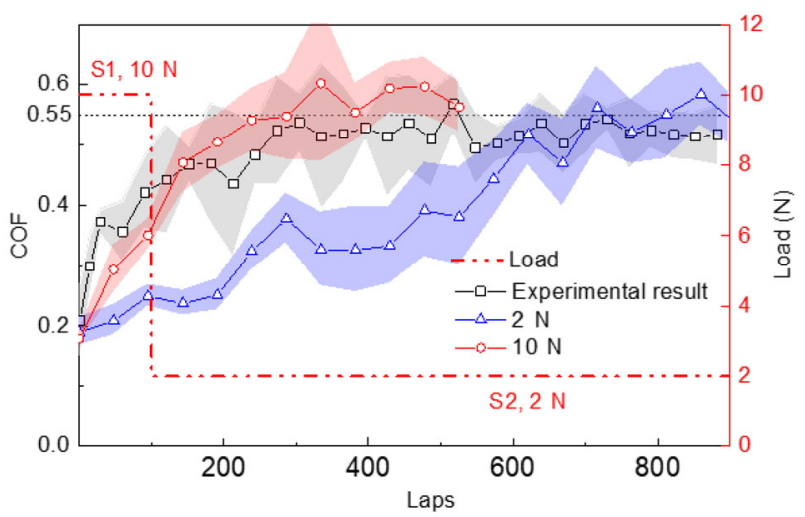

Fig. 3 Comparing COF evolutions between load decrease and constant loads. Symbols represent average COFs; envelopes represent SDs of three repetitions.

Table 2 Test matrix of constant load test.

\begin{tabular}{cccccc}
\hline Test No. & $\begin{array}{c}\text { Contact } \\
\text { load (N) }\end{array}$ & $\begin{array}{c}\text { Contact } \\
\text { pressure } \\
(\mathrm{MPa})\end{array}$ & $\begin{array}{c}\text { Sliding } \\
\text { laps }\end{array}$ & $\begin{array}{c}\text { Sliding } \\
\text { distance } \\
(\mathrm{m})\end{array}$ & Note \\
\hline 3 & 2 & 0.64 & 100 & 3.14 & \\
4 & 2 & 0.64 & 200 & 6.28 & S1(inc) \\
5 & 2 & 0.64 & 1,200 & 37.70 & \\
6 & 10 & 3.18 & 100 & 3.14 & $\mathrm{~S} 1(\mathrm{dec})$ \\
7 & 10 & 3.18 & 500 & 15.71 & \\
\hline
\end{tabular}

observed and analysed by the scanning electron microscopy (SEM) with an in-situ focused ion beam (FIB) and the white light interferometry (WLI). The electron beam was performed at $10 \mathrm{kV}$ and the secondary electron signals were collected. The crosssection was prepared by FIB operated at an energy of $30 \mathrm{kV}$ and a probe current of $50 \mathrm{pA}$. The observation area was chosen as the central line of the wear track to minimise the effect of radius. The galling area fraction covering the cast iron was calculated based on the 3D surface plot generated by WLI. As the original surface is a Gaussian surface, asperities with height of $3 \sigma \approx 500 \mathrm{~nm}$ above the mean surface were identified as the transfer layer, with $\sigma$ being the SD of the original cast iron surface. Particles with the major dimension smaller than $500 \mathrm{~nm}$ may be neglected by this standard. These smaller particles will be proved to have a very limited effect on the macro-scope galling area and hence are not included in the study.

\section{Results}

\subsection{COF evolution}

The COF evolution under load increases from 2 to $10 \mathrm{~N}$ is shown in Fig. 2. The COF was low at the beginning (0.18) and gradually increased to approximately 0.3 at the end of S1. Immediately after the abrupt increase of contact load to $10 \mathrm{~N}$, a rapid increase of COF to the value of 0.55 was observed with a steeper slope from 200 to 400 laps than that before 200 laps. Figure 3 demonstrates the results of COF under the load decrease condition from 10 to $2 \mathrm{~N}$. Under $10 \mathrm{~N}$, the COF began with a value of 0.2 and increased to approximately 0.42 at the end of S1. After the contact load decreased to $2 \mathrm{~N}$, the increasing rate of COF had reduced between 100 laps to approximately 570 laps. It should be noted that 
the COF evolution experiences an unstable period after the decrease of contact load, which has a large fluctuation duration of approximately 500 laps as shown in Fig. 3. Comparing to the COF evolutions obtained under constant contact loads, the change of rate increase before and after load change are clearly presented. In Fig. 2, the COF curve of load change and constant load almost coincide in S1 under $2 \mathrm{~N}$; they separate after 200 laps due to the rapid increase of COF caused by the load increase. The load change system reached its equilibrium at 400 laps, which is between the equilibrium distance of $2 \mathrm{~N}$ (780 laps) and $10 \mathrm{~N}$ (220 laps). In Fig. 3, in S1 under $10 \mathrm{~N}$, the COF curve shows a rapid increase similar to the curve under the load of $10 \mathrm{~N}$. The mismatch between curves of $10 \mathrm{~N}$ and $2-10 \mathrm{~N}$ at the initial 100 laps may be caused by system errors between different test batches. After a reduction of the rate increase of COF by decreasing the load, this system reached the equilibrium at a sliding distance of 600 laps, which is between the evolutions under $10 \mathrm{~N}$ (220 laps) and $2 \mathrm{~N}$ (780 laps). The initial COF and the saturated COF at equilibrium obtained from different conditions were close to the value of 0.18 and 0.55 , respectively, and thus they can be considered as constants in the studied load range, which is independent of the contact pressure.

\subsection{Aluminium transfer layer analysis}

Figure 4 shows the topography of the 'clean' cast iron surface before tests. Compared with the topographies after tests (Figs. 5 and 6), some characteristics of the aluminium transfer which is independent of contact load can be observed. In Fig. 4(b), the height distribution of the clean surface was mainly in the range of $0 \pm 0.5 \mu \mathrm{m}$. Compared with the WLI pictures in Figs. 5 and 6, transfer layers with a clear height increase were formed on the original surface. The top
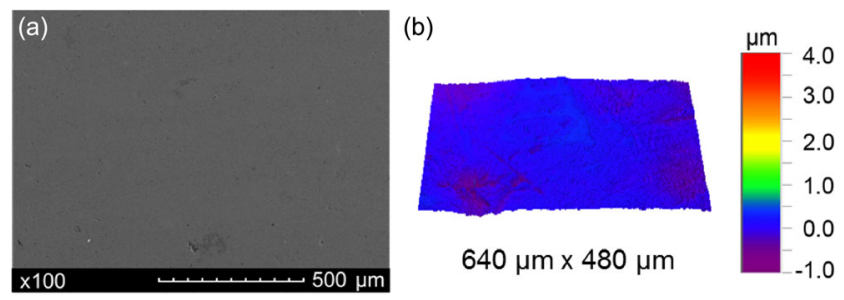

Fig. 4 (a) SEM and (b) WLI topography of the original cast iron surface.
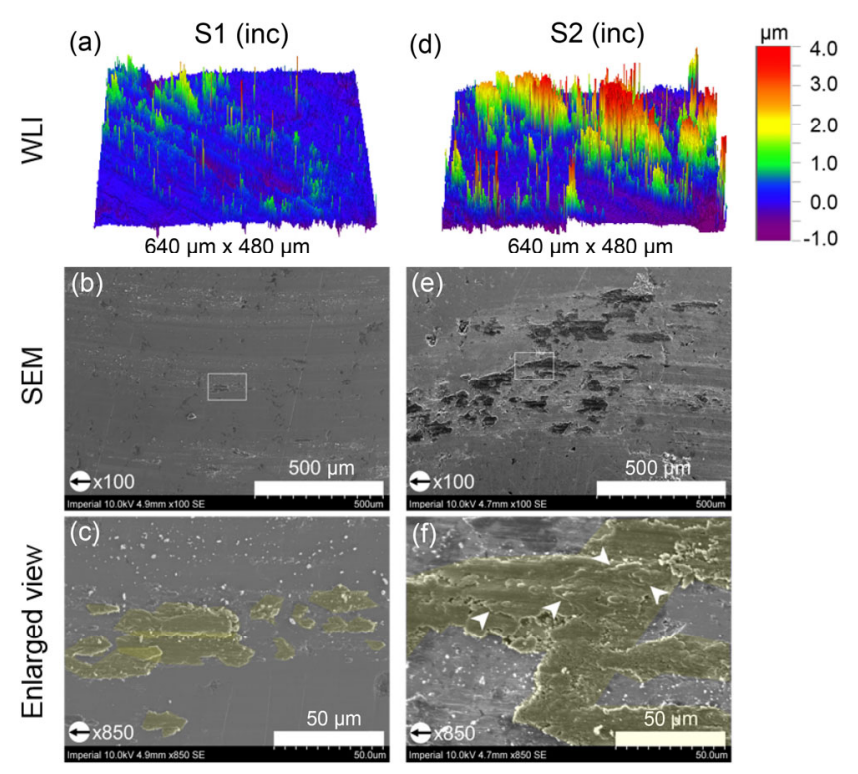

Fig. 5 Topographies of wear tracks at load increase condition: $(\mathrm{a}-\mathrm{c})$ WLI and SEM topographies at the end of sliding under $2 \mathrm{~N}$ (S1(inc)); (d-f) WLI and SEM topographies at the end of sliding under $10 \mathrm{~N}$ (S2(inc)). White arrow: boundaries between individual lumps; yellow area: transfer patches; black arrow: sliding direction.
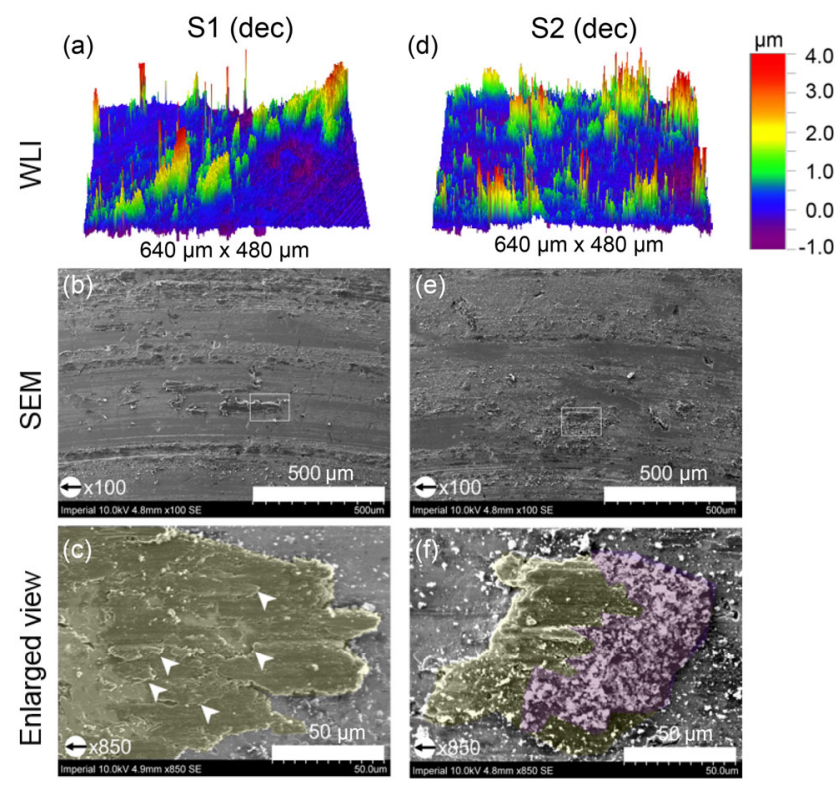

Fig. 6 Topographies of wear tracks at load decrease condition: $(a-c)$ WLI and SEM topographies at the end of sliding under $10 \mathrm{~N}(\mathrm{~S} 1(\mathrm{dec}))$; $(\mathrm{d}-\mathrm{f}) \mathrm{WLI}$ and SEM topographies at the end of sliding under $2 \mathrm{~N}(\mathrm{~S} 2(\mathrm{dec}))$. White arrow: boundaries between individual lumps; yellow area: transfer patches; purple area: layer of small wear particles; black arrow: sliding direction.

view of the transfer layers is presented by the SEM pictures in Figs. 5 and 6, which show that they were comprised of contact patches and loose wear particles. 
The material transfer layer formation in the direction of sliding can be clearly observed in both WLI and SEM pictures from ploughing grooves and transfer tracks.

Figure 5 shows the SEM and WLI topographies of the cast iron surface at the end of sliding under $2 \mathrm{~N}$ (S1(inc)) and later $10 \mathrm{~N}$ (S2(inc)) in the load increase test. In S1, small peaks with the average height of $1 \mu \mathrm{m}$ were generated on the cast iron surface in the direction of sliding (Fig. 5(a)). A slight transfer layer composed of transfer patches can be observed in the SEM picture at this stage (Fig. 5(b)). The enlarged picture (Fig. 5(c)) shows the wear layer was formed by individual transfer lumps (dark coloured transfer patch surrounded by bright boundary) and wear particles (bright particles). The transfer lumps appear to be built in an ellipsoidal shape with the major dimension from 10 to $50 \mu \mathrm{m}$ being aligned in the direction of sliding with micro-scale wear particles scattered around. Overlaps between lumps were rare although were observed in this stage. After sliding under S2 of $10 \mathrm{~N}$, significant height increase of the transfer layer (average of $3 \mu \mathrm{m}$ ) can be observed in Fig. 5(d). Large transfer patches (dark coloured area with major dimensions from 50 to $300 \mu \mathrm{m}$ in the direction of sliding) can be observed (Fig. 5(e)). It is shown from the enlarged view (Fig. 5(f)) that, the dark coloured transfer patches were composed of large transfer lumps (major dimension approximately $100 \mu \mathrm{m})$. Boundaries between lumps and on the top of transfer patches can be observed, which indicates the formation process of either accumulating or overlapping of wear particles. Scattered small wear particles can also be observed around the transfer patches. Figure 6 shows the SEM and WLI topographies of the cast iron surface at the end of sliding under $10 \mathrm{~N}(\mathrm{~S} 1(\mathrm{dec}))$ followed by $2 \mathrm{~N}$ (S2(sec)) in the load decrease test. In the WLI picture of S1 (Fig. 6(a)), a large amount of high transfer layer was generated with an average height of approximately $2 \mu \mathrm{m}$. In the SEM picture (Fig. 6(b)), transfer patches were formed in the direction of sliding with the size and pattern close to the observation of S2 (inc) but with low density and height. In the enlarged picture (Fig. 6(c)), boundaries on the top surface of the transfer patches formed by overlapping and accumulation can also be observed, which is similar to S2 (inc). After sliding of S2, the height of the largest peaks was close to the condition of S1 (dec), but several small peaks in the range less than $1.5 \mu \mathrm{m}$ grew at this stage (Fig. 6(d)). In the SEM picture (Fig. 6(e)), these layers of small peaks were observed as a bright transfer layer composed of small wear particles that covered the whole wear track. In the enlarged view (Fig. 6(f)), a large transfer lump (major dimension of $80 \mu \mathrm{m}$ ) can be observed under the layer of small wear particles. This layer particularly accumulated in the edge area towards the direction of sliding as shown in Fig. 6(f) by a purple shadow.

\subsection{Wear particle analysis}

Pictures of wear particles generated under $10 \mathrm{~N}$ (test 6 , Figs. 7(a)-7(d)) and $2 \mathrm{~N}$ (test 3, Figs. 7(e)-7(h)) were captured on the outer boundary of the wear track.
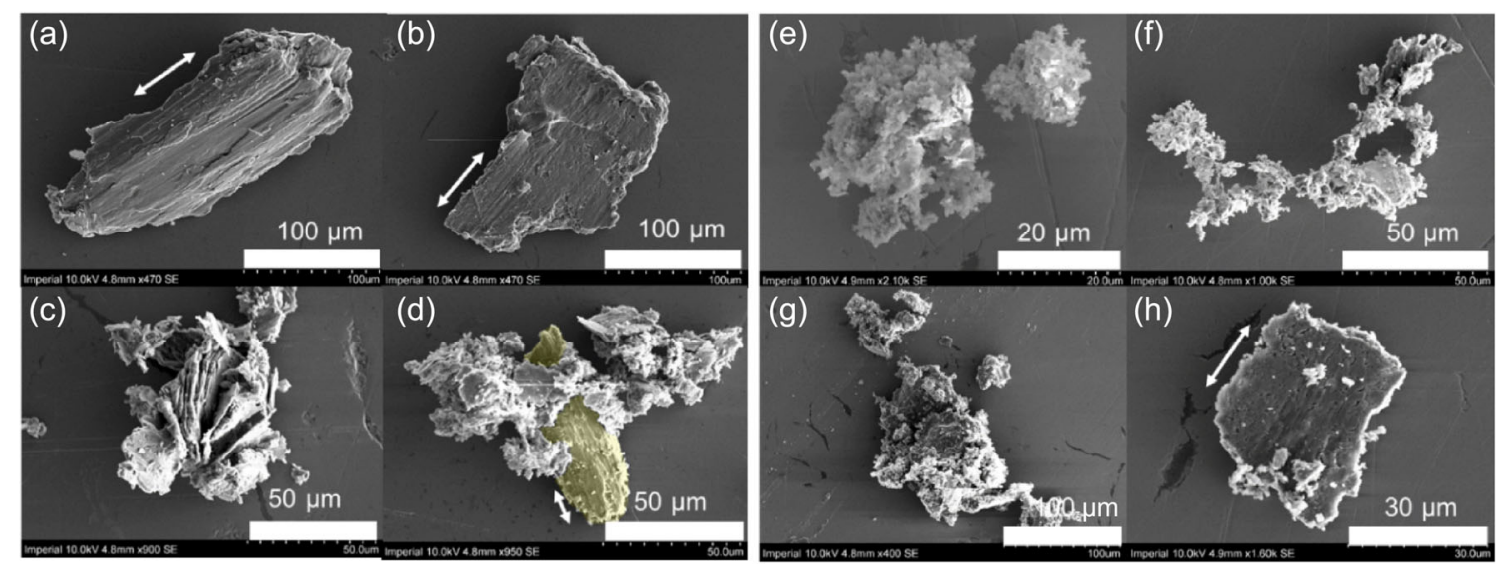

Fig. 7 SEM images of aluminium wear particles obtained at the contact load of (a-d) $10 \mathrm{~N}$ and (e-h) 2 N. Arrows: sliding directions shown by ploughing grooves; yellow area: chip shape particles. 
Under $10 \mathrm{~N}$, large wear particles (with major dimensions between 50 and $300 \mu \mathrm{m}$ ) were generated; under $2 \mathrm{~N}$, the single wear particles are small (with major dimensions less than $30 \mu \mathrm{m}$ ) and likely to cluster together (Figs. 7(f) and 7(g)).

Independent of contact load, certain shapes of single wear particles were observed throughout the tests and can be classified into two catalogues: 1) chip shape particles (Figs. 7(a), 7(b), and 7(h)) and 2) typical adhesive wear particles (Figs. 7(d)-7(g)). Chip shape, which may adhere on the counterpart but detach, is characterised by its ellipsoidal or semi-ellipsoidal outline with ploughing grooves or transfer layer on the top surface in the direction of sliding. For example, in Fig. 7(a), a chip-shape wear particle with contours of small transfer lumps can be observed; its former sliding direction can be inferred by both the direction of its outline major axis as well as the grooves and small transfer lumps. In Figs. 7(b) and 7(h), chip shape particles with relatively flat surfaces and shallow ploughing grooves in the direction of sliding when compared to Fig. 7(a) may indicate their top surfaces, shown in the pictures, were adhered on the cast iron surface instead of contacting the counterpart. In contrast, adhesive wear equiaxed particles present irregular shapes with rough regions of typical shear fracture [59]. For the small irregular wear particles observed at $2 \mathrm{~N}$, the edges present a flake-like shape, which is more likely to accumulate together and form loss structures as shown in Figs. 7(d) and 7(f). In Fig. 7(d), a special cluster was observed, which was formed by a chip-shape wear particle in the middle clustered with adhesive wear particles. In Fig. 7(f), a rope-like cluster was formed with different size and type of small wear particle.

\subsection{FIB cross section analysis}

Figure 8 presents tilted and cross-sectional SEM images of aluminium transfer patches formed on the wear track of test 1 . In Fig. 8(a), transfer patches covered most areas of the cast iron wear track. Boundaries illuminated by yellow shadows separated a few large transfer lumps. A cross section with the width of $4 \mu \mathrm{m}$ was prepared by FIB at a joint of the boundaries to (a)

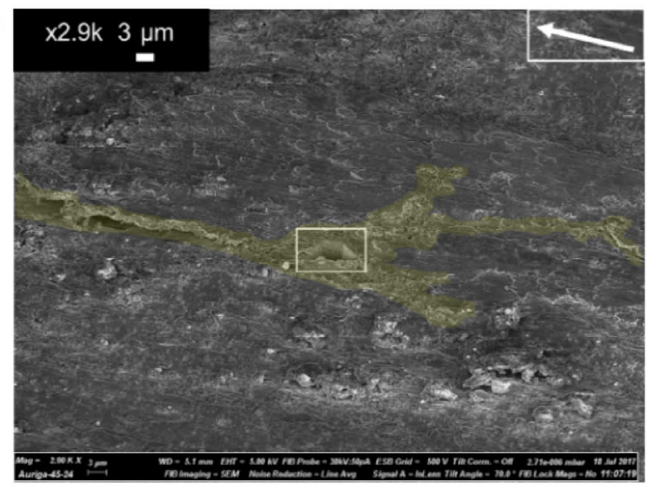

(c)

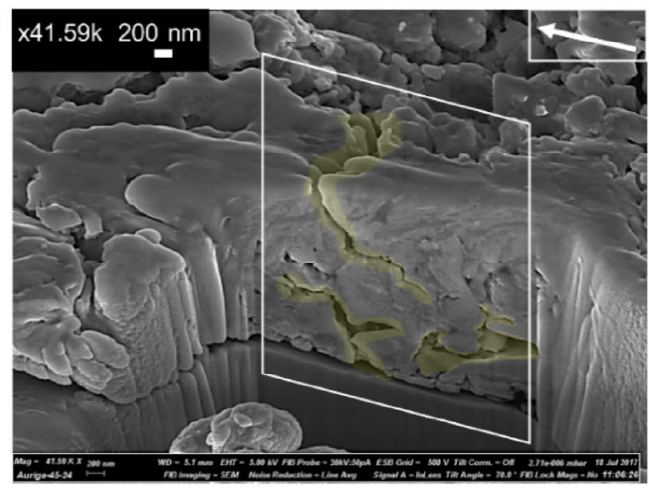

(b)

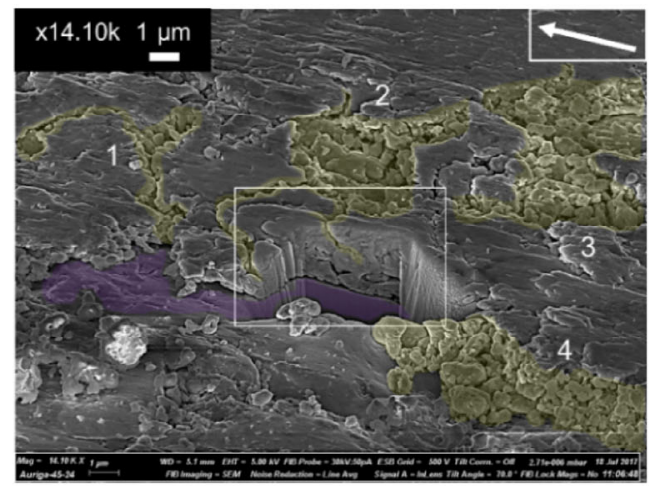

(d)

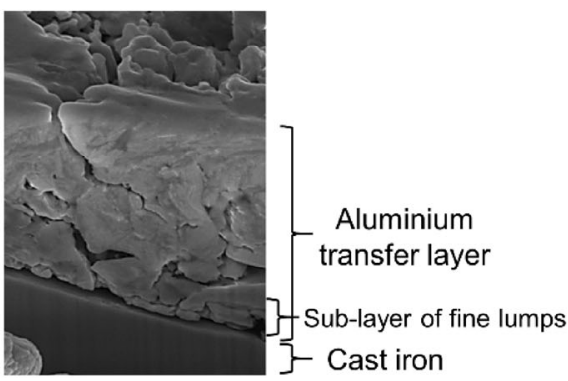

Fig. 8 Tilted topographies of the structure of aluminium transfer layers taken on test 1: (a, b) cross-sectional images through FIB sample preparation, (c) enlarged view of the cross-section, and (d) schematic diagram of layers in the cross-section. Yellow areas: boundaries between wear particles; purple area: cast iron substrate; white arrows: sliding direction. 
enable the observation of the historical formation process of the laminar transfer layers. In the enlarged view (Fig. 8(b)), the boundary between the cast iron substrate and the transfer layer can be clearly observed in the cross-section area. The cross-section of the cast iron presents homogeneous properties with no clear deformation or crack being observed. In contrast, boundaries between wear particles gives an insight of the deformation history where the wear particle experienced plastic deformed from loose wear particles of irregular shapes shown in Fig. 7 into chip shape transfer lump during sliding. As shown in Fig. 8(b), transfer lumps may be crushed and accumulated compactly and leave small spaces at the edge (e.g., boundary 1 in Fig. 8(b)). Otherwise, lumps may accumulate loosely with large gaps formed between them, which were later filled by small wear particles (boundaries 2, 3, and 4 in Fig. 8(b)). A similar phenomenon can also be observed beneath the top surface in Fig. 8(c), where the boundaries between wear particles extended on the cross section and void spaces were formed by loose accumulation. A schematic diagram of the laminar structure of aluminum transfer layer is shown in Fig. 8(d), in which a sub-layer of fine wear particles can be observed at the bottom of the transfer layer.

\subsection{Galling area calculation}

The results of the galling area at various stages under the load increase and decrease conditions are shown in Fig. 9. It was found that galling area fraction, which is defined by the area of cast iron covered by aluminium transfer layer, is a reliable and feasible parameter of measuring the formation process of a transfer layer as well as modelling the contact area between solid aluminium and its transfer layer. The galling area starts from zero at the beginning and gradually increases to a pressure-dependent saturated value with the tribo-system reaching its equilibrium $[4,27]$. The saturated galling areas obtained under constant contact load of 2 and $10 \mathrm{~N}$ are plotted in Fig. 9 and compared with results obtained from load change tests. In Fig. 9(a), S1 stopped before equilibrium and showed a galling area of $15.6 \%$, which is lower than the saturated value (34.3\%) under the same load of $2 \mathrm{~N}$. After sliding at S2 under $10 \mathrm{~N}$ when the system
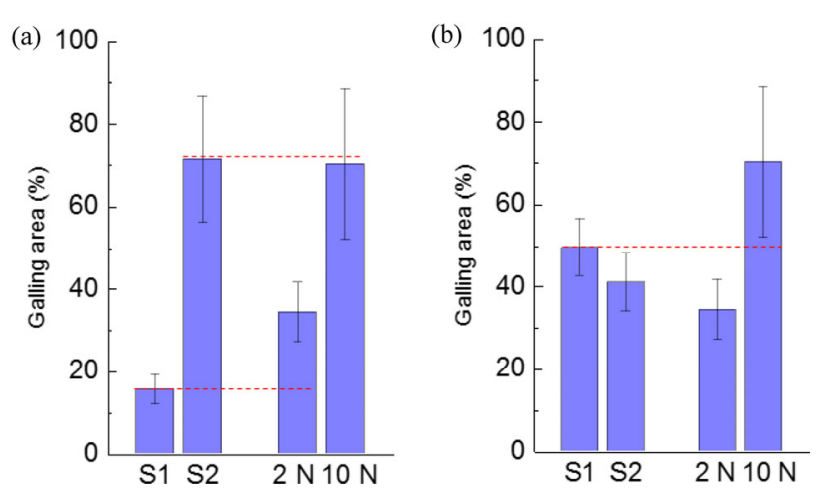

Fig. 9 Galling area (\%) at S1 and S2 under the load (a) increase and (b) decrease conditions compared to the saturated values obtained at constant conditions.

reached equilibrium, a final galling area of $71.4 \%$ was obtained, which is almost equal to the saturated galling area under constant load of $10 \mathrm{~N}(70.2 \%)$. In Fig. 9(b), S1 stopped before equilibrium under $10 \mathrm{~N}$ and showed a galling area of $49.5 \%$. This value is lower than the saturated galling area under a constant load of $10 \mathrm{~N}(70.2 \%)$ but greater than the saturated galling area under a constant load of $2 \mathrm{~N}$ (34.3\%). After sliding at S2 under $2 \mathrm{~N}$, the system reached equilibrium, and a galling area of $41.1 \%$ was obtained. This value is lower than the galling area achieved at $\mathrm{S} 1$ but still greater than the saturated galling area under a constant load of $2 \mathrm{~N}$.

\subsection{COF angular map}

Figure 10 shows the angular maps of COF evolution from tests 1 and 2 . The $x$-axis is set as the angle from $0^{\circ}$ to $360^{\circ}$ corresponding to a cycle of rotation of the cast iron disc. Number of laps were plotted in the $y$-axis. An acquisition rate of $160 \mathrm{~Hz}$ was set to generate approximately 100 points per lap. The coloured bar shows the COF. These angular maps show a spatial and historical distribution of aluminium lumps along the wear track. As the COF increase stems from aluminium transfer, a red spot in the angular maps of COF evolution indicates high COF points where a cluster of aluminium patches or wear particles were accumulated at a certain angle on certain laps on the cast iron surface.

2 and $10 \mathrm{~N}$ presented different features on the angular maps. As shown in Fig. 10(a) from 0 to 200 laps and Fig. 10(b) from 100 to 350 laps, high COF points generated under $2 \mathrm{~N}$ presented a dense but 

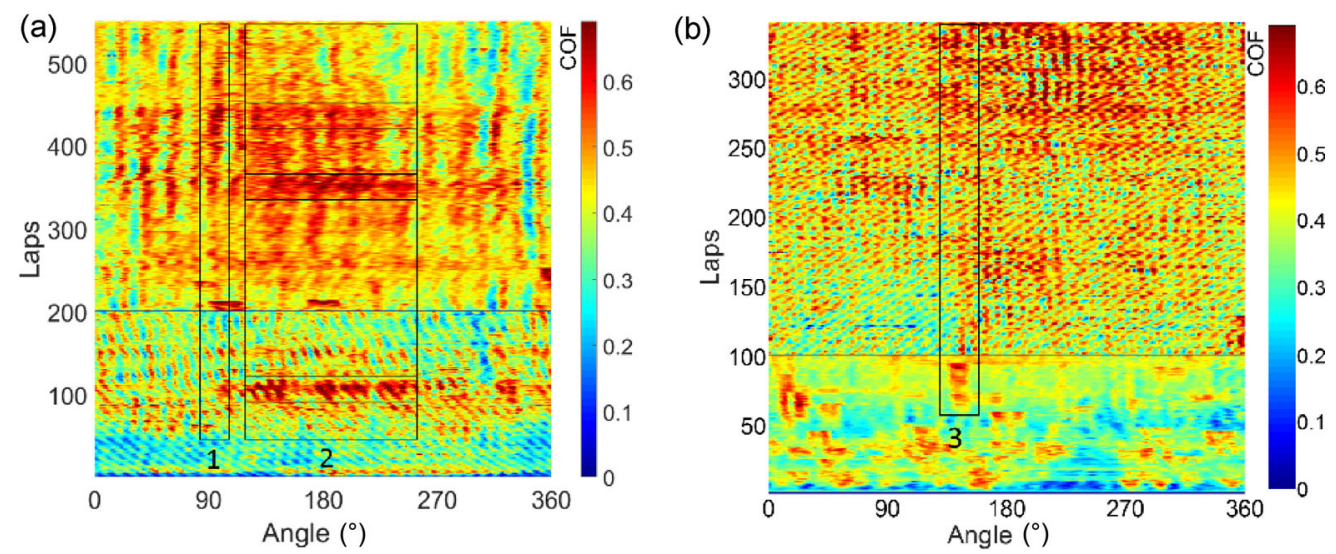

Fig. 10 Angular maps of COF evolutions: (a) load increase test; (b) load decrease test.

short period, which always lasts less than $10^{\circ}$ rotation angle. Comparing to Fig. 10(a) from 200 to 550 laps and Fig. 10(b) from 0 to 100 laps, high COF points generated under $10 \mathrm{~N}$ present a sparse pattern with a relatively long period. This can be caused by: 1) $2 \mathrm{~N}$ was likely to generate small and dense transfer lumps, which is illustrated by SEM micrographics (Figs. 5 and 6), and 2) the small inertia of the weight of $2 \mathrm{~N}$ made it easy to generate a signal by a small disturbance on the wear track.

When an individual lump was formed, it was likely to survive and accumulate more wear particles and finally formed a large transfer patch [13, 29]. This phenomenon can be illustrated with the angular maps by chains of high COF points formed in the direction of the axis of laps, such as area 1 in Fig. 10(a), which is a cluster of lumps that were initially formed at approximately 45 laps in the angle of $95^{\circ}$ under $2 \mathrm{~N}$, grown under $10 \mathrm{~N}$ at the same degree until the end of the test. This survival feature is the most common characteristic of the galling phenomenon and can be observed all over the angular maps. Instead, some lumps may not survive during the whole sliding progress. As shown in Fig. 10(a) in area 2, there is a zone of high COF formed at 120 laps from the angle of $110^{\circ}-250^{\circ}$. This zone disappeared (or known as healing) under $2 \mathrm{~N}$ load condition but regenerated at the $10 \mathrm{~N}$ load condition, which indicates that lumps may be ejected as wear particles but regenerated by secondary transfer based on the former transfer patches. Also, these mechanisms can continuously be observed through load changes. As shown in area 1 in Fig. 10(a) and area 3 in Fig. 10(b), continuous red lines can be observed from increase and decrease of contact load.

\section{Discussion}

\subsection{Relation between friction, wear, and aluminium transfer layer}

The aluminium transfer layer has a significant influence on friction, wear, and surface topography of the aluminium-cast iron tribo-system. The mechanism in this system is identified as a combination of adhesion and abrasion by the observation of transfer patches and ploughings caused by severe adhesive wear and plastic deformation as shown in Figs. 5 and 6. Friction and wear is generated by the direct contact between solid aluminium and cast iron at the beginning. Contact junctions as initial transfer were formed, which may break by shearing inside the soft aluminium asperities and result in subsequent attachment of aluminium to the cast iron surface, and simultaneously generate friction and wear. Transfer patches can also be formed by adhesion of loose wear particles, which contributed to friction and wear by shearing and pressing. As a result, this initial aluminium-cast iron contact generated a COF of 0.18 (shown in Figs. 2 and 3) and a high initial wear rate. After a layer of aluminium had been generated and considerably covered the cast iron asperities, friction and wear should be partly stemmed from cohesion and abrasion between 1) aluminium transfer layer; 2) loose wear particles; and 3) solid aluminium. Several factors may contribute to the COF values. At this stage, aluminium wear particles 
tended to deform plastically, be compressed, and agglomerated into large wear particle clusters (Fig. 7), which may adjust to the velocity difference and partly reduce friction and wear at the interface [60, 61]. However, friction may be increased due to stronger bonds between self-contact aluminium and thus gives a high self-mated COF [32]. Also, it should be noted that, although the asperities of aluminium lumps were subjected to a flattening process, and reached stable structures with a pressure-dependent height and galling area, the integral surface roughness increased due to the material transfer and increased the contribution of ploughing friction. Experimental results of COF increasing show that the mixture of adhesive and ploughing friction may play a dominant role in determining friction than simple mechanical interaction. As shown in the COF evolutions in Figs. 2 and $3, \mathrm{COF}$ s were increased to and maintained at 0.55 when the material transfer reached the equilibrium. The wear rate at the contact interface follows a general adhesive wear model where the initial contact between rough cast iron and aluminium generates a high wear rate on solid aluminium. This wear rate reduced significantly after the soft aluminium transfer layer is formed and gradually polished during the running in stages, which limits ploughing and abrasion. The wear rate finally became constant when the equilibrium was achieved and can be predicted by the Archard's equation [38, 39].

\subsection{Effect of sliding distance}

In the aluminium-cast iron system, the formation of the aluminium transfer layer is related to the increasing sliding distance. At the initial stage of sliding, adhesive and abrasive wear are highly active and were observed by the high initial wear rate. Combined with the effects of external force of shearing and pressure, as well as the high adhesion characteristic of aluminium against steel [32, 62], the loose wear particles are intended to transfer onto the counterpart by two main methods: 1) transfer against rough surface and 2) transfer by adhesive bonding [29, 63]. These initial transfers may trigger secondary transfer by adhering and accumulating loose wear particles on the formed lumps, and further building multi-layer structures as shown in Figs. 5-8. Instead of infinite growth, the formation of aluminium transfer layer will reach a critical condition. In a single lump scale, an aluminium lump may reach a critical size and shape, and be mechanically stable rather than breakdown [23]. However, this mechanical stability may be broken by detachment and ejection. As observations show clear boundary and void spaces between the transfer layer and the cast iron substrate (Fig. 8), as well as the detachment of integral aluminium lumps once adhered on the cast iron surface (Fig. 7), a firm bond between aluminium and cast iron may not always exist. In a macroscopic view, the generation and ejection of loose wear particles and transfer lumps may be active along sliding; attachment and detachment of loose wear particles onto and from the material transfer layer may also exist [6, 30, 34, 64, 65]. As revealed by the angular map of COF (Fig. 10), transfer patches were gradually accumulated at certain positions on the wear track by initial transfer and may trigger secondary transfer at the same position. Some transferred lumps may not survive during sliding, but the rough transfer patches they leave can still trigger a further secondary transfer. Eventually, a pressuredependent steady state was reached as the COF, and wear rate and the galling area become stable. As the equilibrium was achieved, the interface morphology and the volume of transfer layer would become unchanged. Redundant wear particles were ejected out of the contact and a dynamic equilibrium of transfer layer was maintained.

\subsection{Effects of load changing}

Another important characteristic of the transfer layer formation process is its pressure dependency, which simultaneously affects the wear rate and transfer rate of the tribo-system. The effect of pressure on wear rate is well modelled by the Archard's equation and its derivations $[25,30,33-36]$ where the contact load increase will lead to a rapid wear rate increase, which can be observed in experiments as large quantities and size of wear particles were generated after load increased (Figs. 5-7) [66-68]. In addition, large aluminium lumps will be formed from large wear particles under high contact load, which increase both the transfer area and surface roughness and thus increase the possibility of secondary transfer 
and, furthermore, increase the transfer rate. Under constant loads, the effect of load is concluded as: 1) the saturated galling area increases with contact pressure increase, and 2) the duration of the transfer layer formation process is shortened by increasing contact pressure.

Schematic illustrations of the mechanisms under contact load change are shown in Fig. 11. In the load increase condition (test 1), in S1 under $2 \mathrm{~N}$, small wear particles were generated under a low wear rate, which led to a slow formation process of the transfer layer. The formed transfer layer had low height and small transfer patch (Fig. 5) and was unlikely to trigger further transfer, which caused the slow increase of COF in this stage (Fig. 2). In the S2 under $10 \mathrm{~N}$, with higher energy input on the contact, the detachment of aluminium became more severe. The wear particle size dramatically increased and led to a wear rate increase. Large wear particles were likely to adhere on the initial transfer patches formed at $2 \mathrm{~N}$ by secondary transfer processes as shown in Fig. 10. Large transfer lumps were built and gradually accumulated loose wear particles and finally formed a dense transfer layer (Fig. 5). The galling area and COF experienced a steep increase in this stage and finally, the tribosystem reached equilibrium with a saturated condition under $10 \mathrm{~N}$, which is indicated by the equality of the saturated galling areas in Fig. 9(a).

In the load decrease condition (test 2), in S1 under $10 \mathrm{~N}$, combined with a high wear rate, large wear particles were generated immediately and a relatively dense transfer layer with a galling area of $49.5 \%$ at the end of S1 was rapidly formed (Figs. 5(b) and 9(b)). Consequently, COF experienced a rapid increase under $10 \mathrm{~N}$. The COF began at 0.2 and increased to 0.42 within 100 laps of sliding. After a load of $2 \mathrm{~N}$ was applied, small wear particles were generated, which gradually replaced the large particles generated under $10 \mathrm{~N}$ by ejection, and eventually dominated the transfer on cast iron surface. The transfer of small wear particles was more likely to be triggered by the large aluminium lumps formed under $10 \mathrm{~N}$ through the (a)

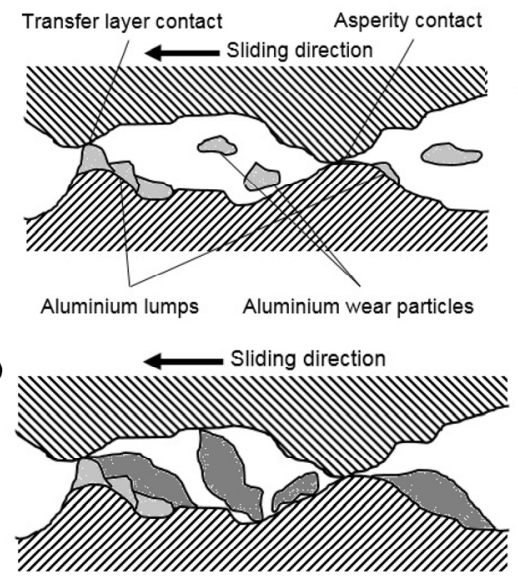

(c)

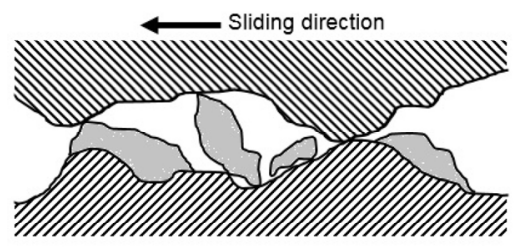

(d)

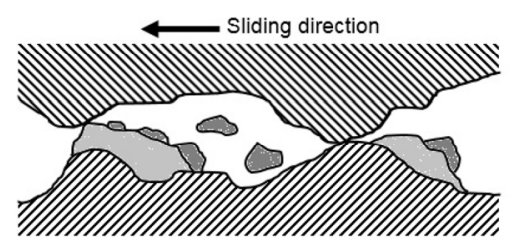

Contact load increase:

1) Under $2 \mathrm{~N}$, small wear particles were generated.

2) Small transfer patches were formed by loose wear particles.

1) When the contact load was increased from 2 to $10 \mathrm{~N}$, small wear particles were ejected and replaced by large ones at the contact.

2) Large transfer patches were formed by large wear particles based on the existing transfer patches.

Contact load decrease:

1) Under $10 \mathrm{~N}$, large wear particles were generated.

2) Large transfer patches were formed.

1) When the contact load decreased from 10 to $2 \mathrm{~N}$, wear particles with smaller sizes werc generated.

2) Small transfer patches were formed on the existing large transfer lumps. Some large transfer lumps may be rejected during sliding.

Fig. 11 Schematic illustrations and descriptions of the mechanisms of the transfer of aluminium to cast iron surface during sliding: $(a, b)$ contact load increase; $(c, d)$ contact load decrease. 
mechanism of secondary transfer which caused a complete change of the morphology of the transfer layer (Fig. 6) with a galling area of $41.1 \%$ (Fig. 9(b)) at the end of S2. This drop of galling area indicates a self-healing process occurred after the load change. In galling phenomenon, healing is reflected by removal of the formed transfer layer and reset of a new stable surface. When the contact load changed from high to low, the transfer layer might experience a process of self-mating to the low contact load, which led to a morphology change with the reduction of the galling area. This process may include recovery of the elastic deformation inside of the transfer lumps formed at high contact load [52], polishing/flattening the high asperities of aluminium lumps, accumulating small wear particles and ejection of unstable large transfer lumps. The increase of COF was largely reduced under S2, and due to the active evolution of the morphology, pronounced oscillations of COF were recorded during this healing process (Fig. 3). From friction measurements, it was found that the healing process under the contact load of $2 \mathrm{~N}$ when dropped from $10 \mathrm{~N}$, required approximately 470 laps sliding distance over the cast iron surface. The final galling area at equilibrium was between the saturated galling area of 2 and $10 \mathrm{~N}$, which indicates some of the aluminium lumps formed under high contact load may survive.

The change of contact load will lead to a rapid change of source rate $\left(\dot{\rho}_{\mathrm{s}}\right)$, which will simultaneously rise or reduce the ejection rate $\left(\dot{\rho}_{\mathrm{e}}\right)$ and further influence the instantaneous volume of the transfer layer $\left(\dot{\rho}_{\mathrm{i}}\right)$. At the load increase condition, in S1 under $2 \mathrm{~N}, \dot{\rho}_{\text {i }}$ gradually increases towards the equilibrium with the converging of $\dot{\rho}_{\mathrm{s}}$ and $\dot{\rho}_{\mathrm{e}}$ to a constant at a relatively low rate. When the load of $10 \mathrm{~N}$ is applied, this running in process is replaced by a faster process of converging where $\dot{\rho}_{\mathrm{s}}$ jumps to a high value due to the rapid wear rate increase and is followed by an increase of $\dot{\rho}_{\mathrm{e}}$. When $\dot{\rho}_{\mathrm{s}}=\dot{\rho}_{\mathrm{e}}$, the equilibrium $\left(\dot{\rho}_{\mathrm{i}}=0\right)$ occurs. At the load decrease condition, in S1 under $10 \mathrm{~N}, \dot{\rho}_{\mathrm{s}}$ begins at a high level and thus generates an initial steep increase of $\dot{\rho}_{\mathrm{e}}$. After load decreases to $2 \mathrm{~N}, \dot{\rho}_{\mathrm{s}}$ and $\dot{\rho}_{\mathrm{e}}$ are reduced to a low rate generated at $2 \mathrm{~N}$ and finally reach the equilibrium slowly.

Based on the results and discussions, three conclusions can be drawn: 1) an increase of contact load will result in an increase of the source rate, the formation rate of transfer layer and the saturated galling area and vice versa, and 2) if the decrease of the saturated galling area caused by the decrease of the corresponding contact load was lower than the already formed galling area, the galling area will decrease by self-healing process. Otherwise, the galling area will continue to increase. 3) COF will continue increasing under any contact load until a saturated value; the rate of increase depends on the contact load.

\section{$5 \quad$ Interactive friction model}

An interactive friction model was established to predict evolutions of $\mathrm{COF}$ and galling area considering the interdependent relationship between friction and galling wear for this aluminium-cast iron tribo-system [58], as expressed in Eqs. (1)-(8).

As the aluminium transfer layer is formed on the surface of cast iron, the contact condition at the interface transforms from aluminium-cast iron contact to the combination of aluminium-cast iron contact and aluminium-aluminium contact, leading to the COF gradually increasing from $\mu_{\mathrm{Al}-\mathrm{CI}}(0.18)$ to $\mu_{\mathrm{Al}-\mathrm{Al}}(0.55)$. Thus the COF, $\mu(t)$, can be modelled as two components: the first stems from aluminium-cast iron contact and the second stems from aluminiumaluminium contact. The contribution of each component to the overall friction is determined by the ratio of the instantaneous galling area, $f(t)$, and the saturated galling area, $f\left(t_{\text {sat }}\right)$, as shown in Eqs. (1) and (2).

$$
\begin{gathered}
\mu(t)=(1-\bar{f}(t)) \mu_{\mathrm{Al}-\mathrm{CI}}+\bar{f}(t) \mu_{\mathrm{Al}-\mathrm{Al}} \\
\bar{f}(t)=\frac{f(t)}{f\left(t_{\mathrm{sat}}\right)}
\end{gathered}
$$

The instantaneous galling area is affected by the entrapped density of wear particles. Based on the modelling of material transfer proposed by de Rooij et al. [23], the instantaneous galling area, $f(t)$, and the saturated galling area, $f\left(t_{\text {sat }}\right)$, can be modelled. These variables are a function of the instantaneous density, $\rho_{\mathrm{i}}(t)$, and the saturated density, $\rho_{\mathrm{i}}\left(t_{\text {sat }}\right)$, respectively, as demonstrated in Eqs. (3) and (4). In 
these equations, $b$ and $\lambda_{1}$ are model constants.

$$
\begin{gathered}
f(t)=b\left(\rho_{\mathrm{i}}(t)\right)^{\lambda_{1}} \\
f\left(t_{\text {sat }}\right)=b\left(\rho_{\mathrm{i}}\left(t_{\text {sat }}\right)\right)^{\lambda_{1}}
\end{gathered}
$$

The normalised density of third body, $\bar{\rho}_{\mathrm{i}}(t)$, is described by the ratio of the instantaneous and saturated third body density, as shown in Eq. (5), and used to calculate the normalised galling area, $\bar{f}(t)$. As discussed in the previous section, the changing rate of entrapped third body, $\dot{\bar{\rho}}_{\mathrm{i}}(t)$, is determined by the difference of the changing rate of newly generated ones, $\dot{\rho}_{\mathrm{s}}(t)$, and the changing rate of the ejected ones from the interface, $\dot{\rho}_{\mathrm{e}}(t)$, as shown in Eq. (6).

$$
\begin{gathered}
\bar{\rho}_{\mathrm{i}}(t)=\frac{\rho_{i}(t)}{\rho_{i}\left(t_{\text {sat }}\right)} \\
\dot{\bar{\rho}}_{\mathrm{i}}(t)=\frac{1}{\rho_{i}\left(t_{\text {sat }}\right)}\left(\dot{\rho}_{\mathrm{s}}(t)-\dot{\rho}_{\mathrm{e}}(t)\right)
\end{gathered}
$$

In the contact load change condition, the accumulation rate of third body at time $t$ is determined by comparing the entrapped third body density at time $t\left(\rho_{\mathrm{i}}(t)\right)$ with the saturated density under the contact load at time $t\left(\rho_{\mathrm{i}}\left(t_{\text {sat }}\right)\right)$. The possible variation rate of entrapped third body, $\dot{\rho}_{\mathrm{i}}(t)$, can be separated into three cases: $\rho_{\mathrm{i}}\left(t_{\text {sat }}\right)>\rho_{\mathrm{i}}(t), \quad \rho_{\mathrm{i}}\left(t_{\text {sat }}\right)=\rho_{\mathrm{i}}(t)$, and $\rho_{\mathrm{i}}\left(t_{\text {sat }}\right)<\rho_{\mathrm{i}}(t)$. For $\rho_{\mathrm{i}}\left(t_{\text {sat }}\right)>\rho_{\mathrm{i}}(t)$, the tribo-system is unsaturated. The saturated amount is larger than the present amount and thus the tribo-system will accumulate more third body to reach the equilibrium. When $\rho_{\mathrm{i}}\left(t_{\text {sat }}\right)=\rho_{\mathrm{i}}(t)$, the equilibrium has been achieved and $\dot{\bar{\rho}}_{\mathrm{i}}(t)=0$. As $\rho_{\mathrm{i}}\left(t_{\text {sat }}\right)<\rho_{\mathrm{i}}(t)$, the saturated entrapped third body is smaller than the present amount of entrapped third body due to contact pressure reduction. The tribo-system is under an 'oversaturation' state and the entrapped third body will be ejected from the interface at a negative rate of $\dot{\bar{\rho}}_{\mathrm{i}}(t)$ until a new equilibrium is achieved. This comparison is conducted by calculating Eq. (7). Integrating this equation and considering the calculation of $\dot{\rho}_{\mathrm{s}}(t)$, $\dot{\rho}_{\mathrm{e}}(t)$, and $\rho_{\mathrm{i}}\left(t_{\text {sat }}\right), \rho_{\mathrm{i}}(t)$ can be calculated, as shown in Eq. (8). The $m$ and $\lambda_{2}$ are model constants, $v(t)$ represents the sliding speed, and $n$ is a model parameter that physically represents the ratio between the initial source rate and its saturated value. Further details regarding the derivation of these equations can be found in Ref. [58].

$$
\begin{gathered}
\dot{\rho}_{\mathrm{i}}(t)=\dot{\bar{\rho}}_{\mathrm{i}}(t)\left(\frac{\rho_{i}\left(t_{\mathrm{sat}}\right)-\rho_{\mathrm{i}}(t)}{1-\bar{\rho}_{\mathrm{i}}(t)}\right) \\
\dot{\bar{\rho}}_{\mathrm{i}}(t)=m P^{\lambda_{2}} v(t)\left[\left(n \dot{\bar{\rho}}_{\mathrm{i}}(t)+1\right)-\bar{\rho}_{\mathrm{i}}(t)\right]
\end{gathered}
$$

The model parameters of the above equations can be determined according to the calibration of experimental results under constant load conditions against predicted results made by the interactive friction model, as shown in Table. 3. The experimental results of load change tests, i.e., load increase and decrease, are then compared with the modelling results and close agreements of COF evolution and galling area are achieved, as shown in Fig. 12.

Table 3 Model parameters.

\begin{tabular}{cccccccc}
\hline Parameter & $m$ & $n$ & $b$ & $\mu_{\mathrm{Al}-\mathrm{Al}}$ & $\mu_{\mathrm{Al}-\mathrm{CI}}$ & $\lambda_{1}$ & $\lambda_{2}$ \\
\hline Value & 0.1 & 15 & 0.43 & 0.18 & 0.55 & 1.6 & 0.7 \\
\hline
\end{tabular}

(a)

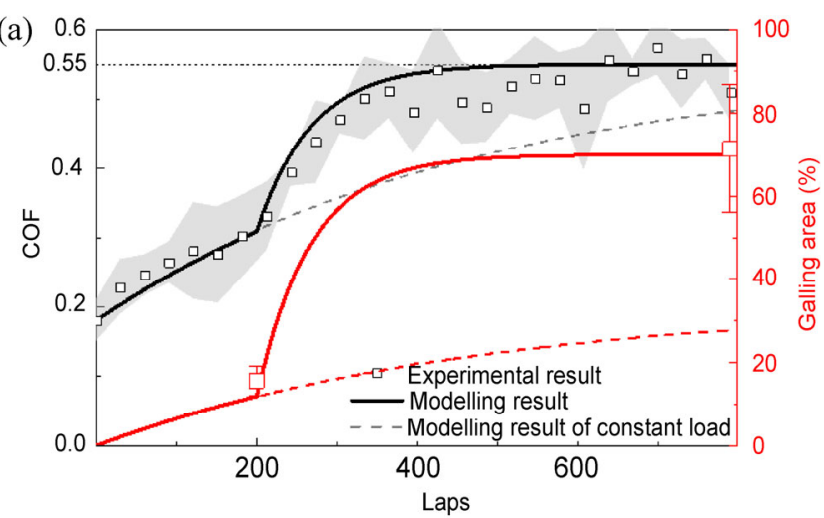

(b)

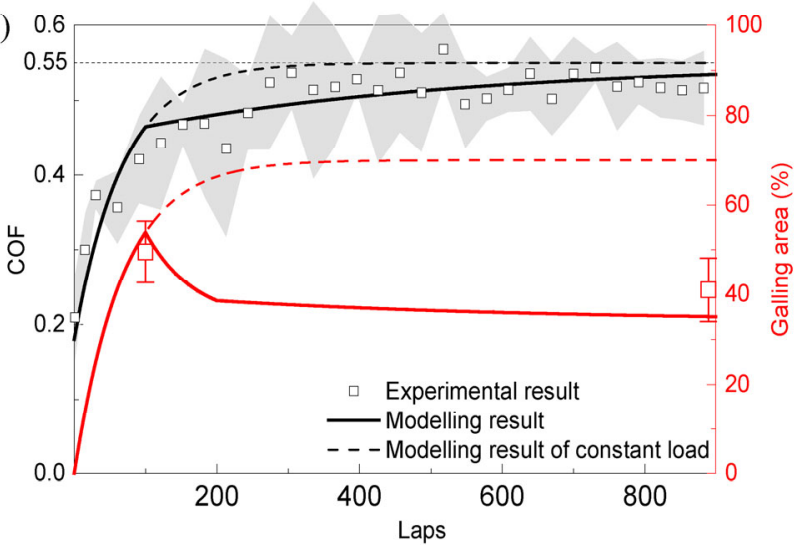

Fig. 12 Modelling results of COF and galling area evolutions under (a) load increase condition and (b) load decrease condition compared to experimental results. 
The formation rate of the transfer layer directly affects the evolutions of COF and galling area. Rapid changes of $\mathrm{COF}$ and galling area evolutions are modelled for both an increasing (Fig. 12(a)) and decreasing (Fig. 12(b)) contact load condition. In Fig. 12(a), the modelling results show the rapid increase of COF and galling area under load increase condition from 2 to $10 \mathrm{~N}$, which reaches the steady state earlier than under a constant load condition of $2 \mathrm{~N}$. In Fig. 12(b), the modelling results show a decrease of the changing rate of COF evolution and a reduction of galling area caused by a decrease of contact load from 10 to $2 \mathrm{~N}$. These modelling results are compared with results modelled under constant loads, between which the effects of load change are clearly presented. Experimental results are presented in scatter diagrams with SDs showing a good agreement being observed, which proves that the developed interactive model is sufficiently robust to predict friction evolution and galling wear under load change conditions.

To study the effect of contact load change, a series of modelling conditions were designed. Two stages of load with nine conditions were set: in S1, the load gradually decreased from 10 to $2 \mathrm{~N}$ with a sliding distance of 200 laps; in S2, the load increased from 2 to $10 \mathrm{~N}$ with a sliding distance of 600 laps. The modelling results of COF and galling area are shown in Fig. 13. In Fig. 13(a), the variation of the rate increase of $\mathrm{COF}$ evolutions caused by contact load change before and after load changing can be observed, where high contact load will lead to an increased rate of $\mathrm{COF}$ and vice versa. Finally, with continuous sliding, the $\mathrm{COF}$ evolutions converge to the saturated COF of 0.55 at the steady state. Figure 13(b) presents the load changing effect on the evolution of the galling area. According to galling area evolution, not only the rate increase but also the saturated galling area are affected by load change. In tests $1-4$, due to the high contact load at S1, the galling areas generated at S1 were already greater than the saturated galling areas of the contact load of S2, which leads to self-healing processes in S2. From tests 6-9, as the saturated galling areas of S2 are not reached by $\mathrm{S1}$, the final galling areas were dependent on the saturated galling area of the contact load under S2. Test 5 with a constant contact load of $6 \mathrm{~N}$ through two stages separates these two groups.
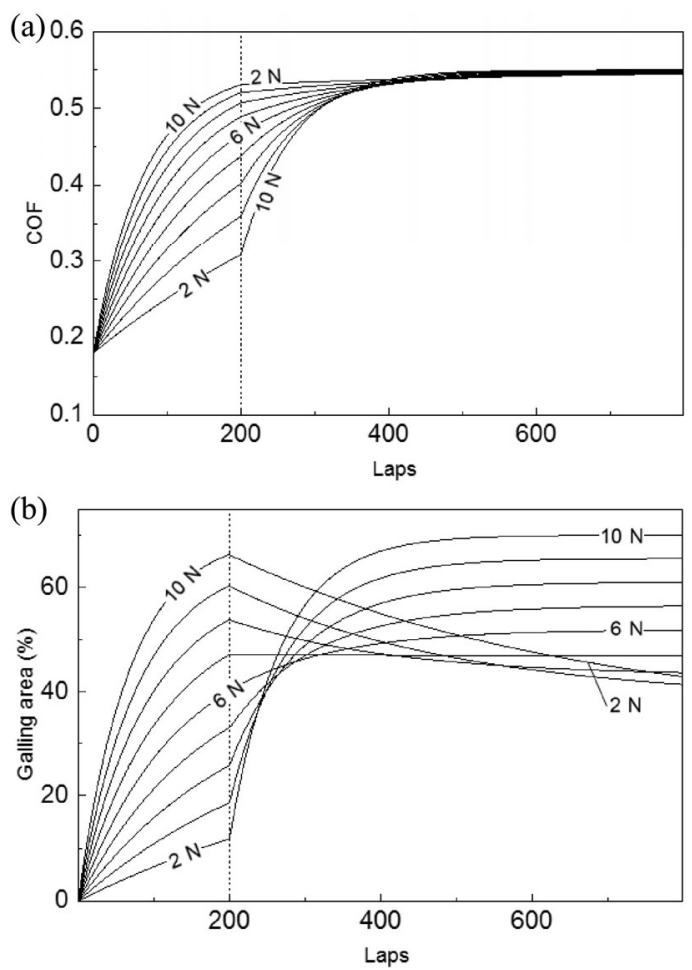

Fig. 13 Modelling results of evolution of (a) COF and (b) galling area under test conditions of Table 4.

Table 4 Modelling conditions.

\begin{tabular}{|c|c|c|c|c|}
\hline \multirow{2}{*}{$\begin{array}{l}\text { Test } \\
\text { No. }\end{array}$} & \multicolumn{2}{|c|}{$\mathrm{S} 1$} & \multicolumn{2}{|c|}{ S2 } \\
\hline & $\begin{array}{l}\text { Load } \\
(\mathrm{N})\end{array}$ & $\begin{array}{l}\text { Sliding } \\
\text { distance }\end{array}$ & $\begin{array}{l}\text { Load } \\
(\mathrm{N})\end{array}$ & $\begin{array}{c}\text { Sliding } \\
\text { distance }\end{array}$ \\
\hline 1 & 10 & 200 laps & 2 & 600 laps \\
\hline 2 & 9 & 200 laps & 3 & 600 laps \\
\hline 3 & 8 & 200 laps & 4 & 600 laps \\
\hline 4 & 7 & 200 laps & 5 & 600 laps \\
\hline 5 & 6 & 200 laps & 6 & 600 laps \\
\hline 6 & 5 & 200 laps & 7 & 600 laps \\
\hline 7 & 4 & 200 laps & 8 & 600 laps \\
\hline 8 & 3 & 200 laps & 9 & 600 laps \\
\hline 9 & 2 & 200 laps & 10 & 600 laps \\
\hline
\end{tabular}

Clear changes of the increasing rate of COF and galling area before and after load change can be observed with contact load of S2 gradually increasing from lower to higher than S1.

\section{Conclusions}

In this paper, experiments with a step change of contact load were conducted between AA6082 and G3500 
to investigate the galling conditions experienced in metal forming operations. It has been found that rapid changes in the contact load result in rapid changes in the evolutions of transfer layer formation and COF. It was also found that the pressure and history dependency of transfer layer and COF which was discovered under constant load condition was also applicable for load change conditions. In addition, a new phenomenon was found in this study, where the formed transfer layer may partly survive after a reduction in contact load and thus affect the final galling area. A mechanical-based model for predicting galling area and COF evolution under load changing conditions has been described in the paper and showed reasonable agreement when compared to the experimental results. This model could therefore be used to predict tool damage caused by galling in aluminium metal forming processes, in which the multi-cycle operations with long sliding distance and rapid load changes are common. As galling is one of the most significant tool damage phenomena in aluminium forming, the successful modelling of dynamic galling will improve the prediction of tool life and assist in identifying critical failure locations on tools.

The obtained findings are summarised as follows:

1) The transition state of aluminium-cast iron tribosystem is determined by the competition between the generation and ejection of loose wear particles or third body at the interface. When equilibrium is achieved, the generation rate decreases and achieves dynamic equilibrium with the increasing ejection rate.

2) Contact load change will disequilibrate and rebuild the dynamic balance between generation and ejection of wear particles or third body. High load will increase the generation rate and ejection rate of third body and vice versa.

3) In the running-in period, the saturation level and formation of the transfer layer are pressure dependent, where a high contact pressure will reduce the transition period and increase the saturation transfer volume at the steady state and vice versa.

4) The decrease of contact load may lead to a period of self-healing of the morphology where a series of secondary transfer mechanisms were triggered and a mixed transfer layer of aluminium lumps and fine equiaxed particles were formed, which resulted in interactive oscillations of COF evolution and a partial decrease of galling area.

\section{Acknowledgements}

This study was supported by China Scholarship Council (CSC) (Grant No. 201706230235). CSC is a national institution that supports Chinese students to participate in overseas M.S. and Ph.D. programs. This study was also funded by Horizon 2020: research and innovation program as part of the project 'LoCoMaTech' (Grant No. 723517). In addition, the strong support from the Institute of Automation, Heilongiiang Academy of Sciences, for this funded research is much appreciated.

Open Access This article is licensed under a Creative Commons Attribution 4.0 International License, which permits use, sharing, adaptation, distribution and reproduction in any medium or format, as long as you give appropriate credit to the original author(s) and the source, provide a link to the Creative Commons licence, and indicate if changes were made.

The images or other third party material in this article are included in the article's Creative Commons licence, unless indicated otherwise in a credit line to the material. If material is not included in the article's Creative Commons licence and your intended use is not permitted by statutory regulation or exceeds the permitted use, you will need to obtain permission directly from the copyright holder.

To view a copy of this licence, visit http://creativecommons.org/licenses/by/4.0/.

\section{References}

[1] Smith R, Doran M, Gandy D, Babu S, Wu L, Ramirez A J, Anderson P M. Development of a gall-resistant stainlesssteel hardfacing alloy. Mater Des 143: 38-48 (2018)

[2] Dohda K, Yamamoto M, Hu C L, Dubar L, Ehmann K F. Galling phenomena in metal forming. Friction 9(4): 665-685 (2021)

[3] Pujante J, Vilaseca M, Casellas D, Riera M D. The role of adhesive forces and mechanical interaction on material transfer in hot forming of aluminium. Tribol Lett 59(1): 10 (2015) 
[4] Podgornik B, Hogmark S, Pezdirnik J. Comparison between different test methods for evaluation of galling properties of surface engineered tool surfaces. Wear 257(7-8): 843-851 (2004)

[5] Olsson D D, Bay N, Andreasen J L. Analysis of pick-up development in punching. CIRP Ann 51(1): 185-190 (2002)

[6] Riahi A R, Alpas A T. Adhesion of AA5182 aluminum sheet to DLC and TiN coatings at $25^{\circ} \mathrm{C}$ and $420{ }^{\circ} \mathrm{C}$. Surf Coat Technol 202(4-7): 1055-1061 (2007)

[7] Sabatini G, Ceschini L, Martini C, Williams J A, Hutchings I M. Improving sliding and abrasive wear behaviour of cast A356 and wrought AA7075 aluminium alloys by plasma electrolytic oxidation. Mater Des 31(2): 816-828 (2010)

[8] Dong Y C, Zheng K L, Fernandez J, Li X Y, Dong H S, Lin J G. Experimental investigations on hot forming of AA6082 using advanced plasma nitrocarburised and CAPVD WC: C coated tools. J Mater Process Technol 240: 190-199 (2017)

[9] Heilmann P, Don J, Sun T C, Rigney D A, Glaeser W A. Sliding wear and transfer. Wear 91(2): 171-190 (1983)

[10] Yang X, Zhang Q L, Zheng Y, Liu X C, Politis D, Fakir O E, Wang L L. Investigation of the friction coefficient evolution and lubricant breakdown behaviour of $\{\mathrm{AA}\}\}_{7075}$ aluminium alloy forming processes at elevated temperatures. Int $J$ Extreme Manuf 3(2): 025002 (2021)

[11] Decrozant-Triquenaux J, Pelcastre L, Courbon C, Prakash B, Hardell J. High temperature tribological behaviour of PVD coated tool steel and aluminium under dry and lubricated conditions. Friction 9(4): 802-821 (2021)

[12] Landheer D, Zaat J H. The mechanism of metal transfer in sliding friction. Wear 27(1): 129-145 (1974)

[13] Schedin E. Galling mechanisms in sheet forming operations. Wear 179(1-2): 123-128 (1994)

[14] Moshkovich A, Perfilyev V, Bendikov T, Lapsker I, Cohen H, Rapoport L. Structural evolution in copper layers during sliding under different lubricant conditions. Acta Mater 58(14): 4685-4692 (2010)

[15] Rigney D A, Karthikeyan S. The evolution of tribomaterial during sliding: A brief introduction. Tribol Lett 39(1): 3-7 (2010)

[16] Mishra A, Kad B K, Gregori F, Meyers M A. Microstructural evolution in copper subjected to severe plastic deformation: Experiments and analysis. Acta Mater 55(1): 13-28 (2007)

[17] Scharf T W, Kotula P G, Prasad S V. Friction and wear mechanisms in $\mathrm{MoS}_{2} / \mathrm{Sb}_{2} \mathrm{O}_{3} / \mathrm{Au}$ nanocomposite coatings. Acta Mater 58(12): 4100-4109 (2010)

[18] Hu J Q, Song H X, Sandfeld S, Liu X M, Wei Y G. Multiscale study of the dynamic friction coefficient due to asperity plowing. Friction 9(4): 822-839 (2021)
[19] Kim H J, Windl W, Rigney D. Structure and chemical analysis of aluminum wear debris: Experiments and $a b$ initio simulations. Acta Mater 55(19): 6489-6498 (2007)

[20] Kim H J, Karthikeyan S, Rigney D. The structure and composition of aluminum wear debris generated by unlubricated sliding in different environments. Wear 263(1-6): 849-857 (2007)

[21] Liu Y, Zhu B, Wang K, Li S Q, Zhang Y S. Friction behaviors of 6061 aluminum alloy sheets in hot stamping under dry and lubricated conditions based on hot strip drawing test. Tribol Int 151: 106504 (2020)

[22] de Rooij M B, Schipper D J. Analysis of material transfer from a soft workpiece to a hard tool: Part II-Experimental verification of the proposed lump growth model. J Tribol 123(3): 474-478 (2001)

[23] de Rooij M B, van der Linde G, Schipper D J. Modelling material transfer on a single asperity scale. Wear 307(1-2): 198-208 (2013)

[24] Hanson M, Hogmark S, Jacobson S. Influence from tool roughness on the risk of work material adhesion and transfer. Mater Manuf Process 24(7-8): 913-917 (2009)

[25] Fillot N, Iordanoff I, Berthier Y. Wear modeling and the third body concept. Wear 262(7-8): 949-957 (2007)

[26] Österle W, Dmitriev A I, Kloß H. Possible impacts of third body nanostructure on friction performance during dry sliding determined by computer simulation based on the method of movable cellular automata. Tribol Int 48: 128-136 (2012)

[27] Kragelsky I V. Friction and Wear. Moscow (Russia): Mashinostroenie, 1968: 480.

[28] Bowden F P, Tabor D. The Friction and Lubrication of Solids. New York (USA): Oxford university press, 2001.

[29] Heinrichs J, Olsson M, Jacobson S. Mechanisms of material transfer studied in situ in the SEM: Explanations to the success of DLC coated tools in aluminium forming. Wear 292-293: 49-60 (2012)

[30] Dwivedi D K. Adhesive wear behaviour of cast aluminiumsilicon alloys: Overview. Mater Des 19802015 31(5): 2517-2531 (2010)

[31] Kato K. Wear in relation to friction-A review. Wear 241(2): 151-157 (2000)

[32] Bhushan B. Introduction to Tribology. 2nd edn. Chichester (UK): John Wiley \& Sons, Ltd, 2013.

[33] Kato K. Classification of wear mechanisms/models. Proc Inst Mech Eng Part J: J Eng Tribol 216(6): 349-355 (2002)

[34] Deuis R L, Subramanian C, Yellup J M. Dry sliding wear of aluminium composites-A review. Compos Sci Technol 57(4): 415-435 (1997)

[35] Hu Y R, Yuan X, Ma G J, Masen M A, Wang L L. Tool-life 
prediction under multi-cycle loading during metal forming: A feasibility study. Manufacturing Rev 2: 28 (2015)

[36] Ma G J, Wang L L, Gao H X, Zhang J, Reddyhoff T. The friction coefficient evolution of a TiN coated contact during sliding wear. Appl Surf Sci 345: 109-115 (2015)

[37] Aghababaei R, Zhao K. Micromechanics of material detachment during adhesive wear: A numerical assessment of Archard's wear model, in press, DOI 10.1016/ j.wear.2021.203739.

[38] Yang L J. An integrated transient and steady-state adhesive wear model. Tribol Trans 46(3): 369-375 (2003)

[39] Yang L J. A test methodology for the determination of wear coefficient. Wear 259(7-12): 1453-1461 (2005)

[40] Godet M. Third-bodies in tribology. Wear 136(1): 29-45 (1990)

[41] Diomidis N, Mischler S. Third body effects on friction and wear during fretting of steel contacts. Tribol Int 44(11): 1452-1460 (2011)

[42] Marques F, Flores P, Pimenta Claro J C, Lankarani H M. A survey and comparison of severalfriction force models for dynamic analysis of multibody mechanical systems. Nonlinear Dyn 86(3): 1407-1443 (2016)

[43] Berger E J. Friction modeling for dynamic system simulation. Appl Mech Rev 55(6): 535-577 (2002)

[44] Kim Y S, Jain M K, Metzger D R. Determination of pressuredependent friction coefficient from draw-bend test and its application to cup drawing. Int J Mach Tools Manuf 56: 69-78 (2012)

[45] Lee J Y, Barlat F, Lee M G. Constitutive and friction modeling for accurate springback analysis of advanced high strength steel sheets. Int J Plast 71: 113-135 (2015)

[46] Gil I, Mendiguren J, Galdos L, Mugarra E, de Argandoña E $S$. Influence of the pressure dependent coefficient of friction on deep drawing springback predictions. Tribol Int 103: 266-273 (2016)

[47] Tamai Y, Inazumi T, Manabe K I. FE forming analysis with nonlinear friction coefficient model considering contact pressure, sliding velocity and sliding length. $J$ Mater Process Technol 227: 161-168 (2016)

[48] Wang W R, Zhao Y Z, Wang Z M, Hua M, Wei X C. A study on variable friction model in sheet metal forming with advanced high strength steels. Tribol Int 93: 17-28 (2016)

[49] Hu Y, Wang L, Politis D J, Masen M A. Development of an interactive friction model for the prediction of lubricant breakdown behaviour during sliding wear. Tribol Int 110: 370-377 (2017)

[50] Yang X, Liu X, Liu H L, Politis D J, Leyvraz D, Wang L L. Experimental and modelling study of friction evolution and lubricant breakdown behaviour under varying contact conditions in warm aluminium forming processes. Tribol Int 158: 106934 (2021)

[51] Shisode M, Hazrati J, Mishra T, de Rooij M, van den Boogaard T. Mixed lubrication friction model including surface texture effects for sheet metal forming. $J$ Mater Process Technol 291: 117035 (2021)

[52] Karupannasamy D K, Hol J, de Rooij M B, Meinders T, Schipper D J. A friction model for loading and reloading effects in deep drawing processes. Wear 318(1-2): 27-39 (2014)

[53] Deng L, Mozgovoy S, Hardell J, Prakash B, Oldenburg M. Development of a tribological test programme based on press hardening simulations. Tribol Lett 65(2): 43 (2017)

[54] Meng B, Fu M W, Fu C M, Chen K S. Ductile fracture and deformation behavior in progressive microforming. Mater Des 83: 14-25 (2015)

[55] Chan W L, Fu M W, Lu J. Experimental and simulation study of deformation behavior in micro-compound extrusion process. Mater Des 32(2): 525-534 (2011)

[56] Holmberg S, Thilderkvist P. Influence of material properties and stamping conditions on the stiffness and static dent resistance of automotive panels. Mater Des 23(8): 681-691 (2002)

[57] Pereira M P, Yan W, Rolfe B F. Sliding distance, contact pressure and wear in sheet metal stamping. Wear 268(11-12): 1275-1284 (2010)

[58] Hu Y, Zheng Y, Politis D J, Masen M A, Cui J, Wang L. Development of an interactive friction model to predict aluminum transfer in a pin-on-disc sliding system. Tribol Int 130: 216-228 (2019)

[59] Stachowiak G P, Stachowiak G W, Podsiadlo P. Automated classification of wear particles based on their surface texture and shape features. Tribol Int 41(1): 34-43 (2008)

[60] Wang L, He Y, Zhou J, Duszczyk J. Effect of temperature on the frictional behaviour of an aluminium alloy sliding against steel during ball-on-disc tests. Tribol Int 43(1-2): 299-306 (2010)

[61] Zhou Z, Rainforth W M, Luo Q, Hovsepian P E, Ojeda J J, Romero-Gonzalez M E. Wear and friction of TiAlN/VN coatings against $\mathrm{Al}_{2} \mathrm{O}_{3}$ in air at room and elevated temperatures. Acta Mater 58(8): 2912-2925 (2010)

[62] Suh N P, Tabor D. Tribophysics. Englewood Cliffs (USA): Prentice-Hall, 1986.

[63] Hu Y, Zheng Y, Politis D J, Wang L, Gharbi M M. Investigation of galling behaviors between an aluminum alloy and metal forming tool. In Proceeding of the 3rd International Conference on Advanced High Strength Steel and Press Hardening (ICHSU2016), Xi'an, China, 2018: 438-442.

[64] Rabinowicz E. An adhesive wear model based on variations 
in strength values. Wear 63(1): 175-181 (1980)

[65] Korres S, Feser T, Dienwiebel M. In situ observation of wear particle formation on lubricated sliding surfaces. Acta Mater 60(1): 420-429 (2012)

[66] Costa H L, Oliveira Junior M M, de Mello J D B. Effect of debris size on the reciprocating sliding wear of aluminium. Wear 376-377: 1399-1410 (2017)

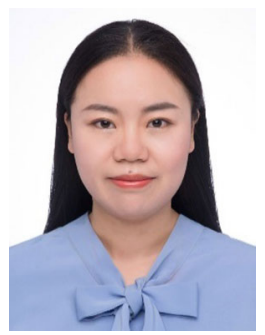

Xiao YANG. She is a Ph.D. candidate in the Department of Mechanical Engineering at Imperial College London, UK. She received her M.S. degree in the Institute of Forming

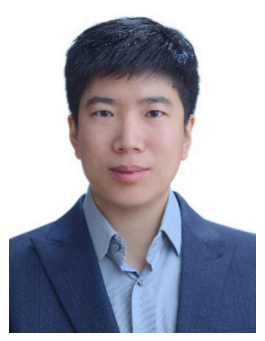

Yiran HU. He received his Ph.D. degree in mechanical engineering from Imperial College London, UK

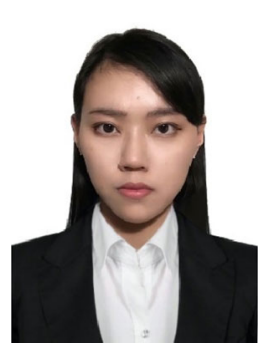

Lemeng ZHANG. She is studying for her M.S. degree in mechanical engineering at Imperial College London, UK. She obtained her B.S. degree in 2020 from University

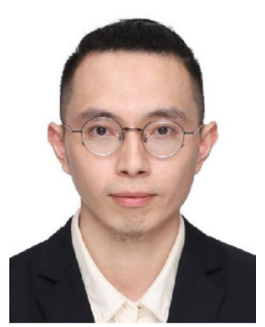

Yang ZHENG. He received his Ph.D. degree in mechanical engineering from the Imperial College London, UK in 2020 . He is currently working
[67] Xie Y, Bhushan B. Effects of particle size, polishing pad and contact pressure in free abrasive polishing. Wear 200(1-2): 281-295 (1996)

[68] Zhang J, Alpas A T. Transition between mild and severe wear in aluminium alloys. Acta Mater 45(2): 513-528 (1997)

Technology and Equipment, Shanghai Jiao Tong University, China in 2017. Her current research focuses on friction characterisation and interfacial behaviours in hot/warm metal forming processes.

in 2018. He is currently working as a data engineer at Huawei Technologies Co., Ltd. His research interest includes prognostic health management.

College London, UK. Her current research focuses on the development of an autonomous laboratory system to study the friction and lubricant breakdown during hot metal forming.

as a senior engineer of Huawei Technologies Co., Ltd. His research interests include working towards reliable and safe AI by integrating prior knowledge. 


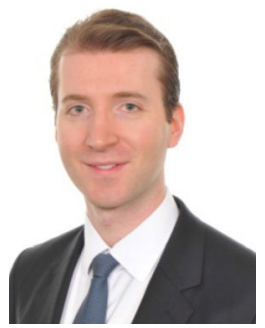

Denis J. POLITIS. He is a lecturer and head of the Manufacturing and Materials Modelling laboratory in the Department of Mechanical and Manufacturing Engineering at the University of Cyprus. He has more

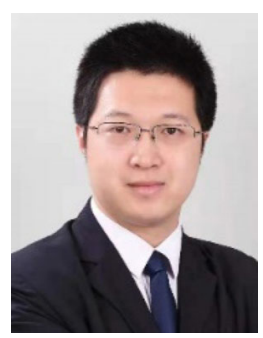

Xiaochuan LIU. He is an assistant professor in the Department of Mechanical Engineering, Xi'an Jiaotong University, China, who obtained his B.Eng. degree from University of Sheffield, M.Sc. and

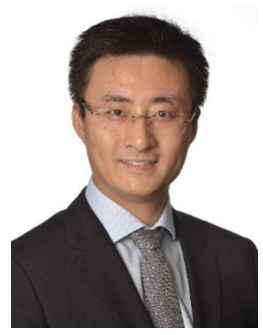

Li-liang WANG. He is the head of Metal Forming and Modelling Group at Imperial College London. His major research interests include the design and development of than 10-year research experience in sheet metal forming and forging technologies. He has worked on numerous research projects in collaboration with industrial companies that have been sponsored by European FP7 and H2020 grants.

Ph.D. degrees from Imperial College London. His research is focused on the material properties and modelling, cloud FEA and advanced forming technology for lightweight materials, including aluminium alloys, titanium alloys and composites.

advanced metal forming technologies and manufacturing system. His work has made fundamental contributions to the characterization and modelling of materials and interfacial behaviours of engineering materials. 